\title{
Spinal segmental sensitization as a common origin of chronic non-specific regional musculoskeletal pain: Review of its pathophysiology and diagnosis
}

\author{
Tomas Nakazato $^{1 *}$, Pedro Romero ${ }^{2}$ and Mauro Guzzardo ${ }^{3}$ \\ ${ }^{1}$ Specialist in Physical Medicine and Rehabilitation. Medical Director of Cedomuh (Specialized Clinic in Muscle and Bone Pain), Lima, Peru \\ ${ }^{2}$ Specialist in Physical Medicine and Rehabilitation. Medical Director of the Centre for Pain Therapy and Comprehensive Rehabilitation, Lima, Peru \\ ${ }^{3}$ Specialist in Physical Medicine and Rehabilitation. Former Director of the Musculoskeletal Rehabilitation Committee of the Latin American Rehabilitation Medical Association \\ (AMLAR). Member of Pain Research Training Team (EFID) and the University of Rosario. Rosario, Argentina.
}

\begin{abstract}
Musculoskeletal pain involving a region of the spine with radiation to the head, trunk, or extremities is relatively common in daily medical practice, such as upperneck pain with headache, lower-neck pain and discomfort in the shoulders and arms, or low-back pain with sciatica. The instability of a vertebral segment produces a persistent barrage of nociceptive impulses that trigger peripheral and central sensitization phenomena, affecting the metamere innervated by the corresponding nerve root. This process produces clinical manifestations of hyperalgesia and/or allodynia in dermatomes, myotomes, and sclerotomes with a typical regional distribution known as spinal segmental sensitization (SSS). The activation of new peripheral nociceptive foci within the affected metamere can further aggravate the clinical picture. This disorder is usually classified as non-specific for being a somatosensory nervous system dysfunction without evident structural damage, which can lead to confusion since the magnitude of pain and disability reported by the patient appear to be disproportionate to the findings of auxiliary tests. In the absence of a timely diagnosis and adequate treatment, patients may resort to alternative therapies, which often do not solve the problem. The use of a standardized set of diagnostic criteria will help clinicians identify SSS and help researchers conduct studies in homogeneous populations. This review of its pathophysiology provides a foundation for rationally and systematically establishing the best treatment schemes and thus will benefit the many patients who suffer from this syndrome, which represents a challenge for medicine today.
\end{abstract}

\section{Introduction}

Headaches of cervical origin [1-3], sometimes accompanied by dizziness [4,5]. Cervicalgia's radiate to the shoulders and arms [68]. Dorsalgias refer to the chest wall and abdomen [9-12]. Low-back

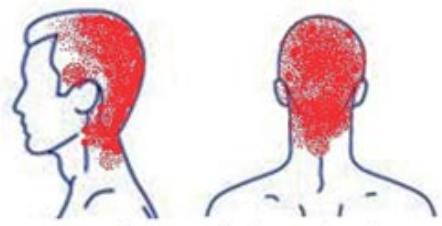

Cervicogenic headache

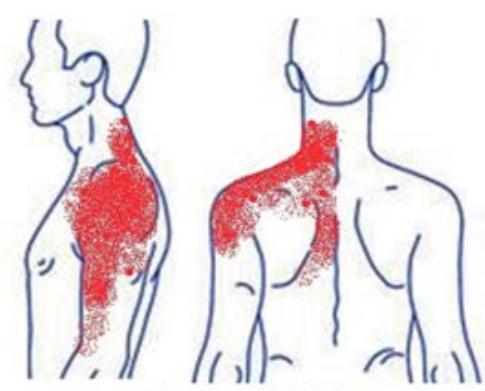

Cervicobrachialgia

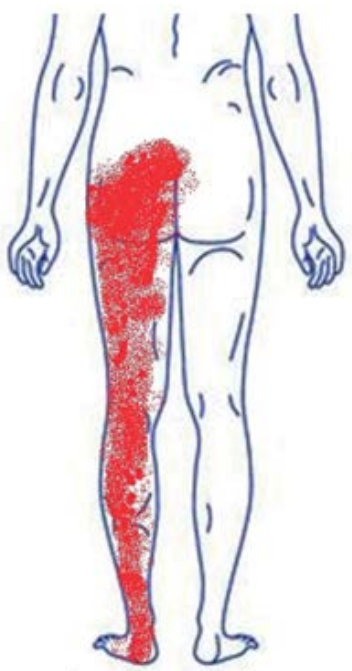

Lumbosciatica.
Figure 1. Regional pain that includes a segment of the spine with radiation to the head, trunk or extremities is relatively common in daily medical practice. If no evidence of nerve damage is found, the condition is usually classified as "non-specific". pain radiates to the lower limbs or sciatica [13-16]. Regional pain associated with the head, trunk, or upper or lower extremities that includes a segment of the spine is relatively common in daily medical practice, creating confusion when symptoms overlap [17] (Figure 1). If radiculopathy is established, the diagnosis of this clinical picture is recognized without further discussion. If no evidence of nerve damage is found, the condition is classified as a non-specific syndrome, and the diagnosis is based on the affected painful territory, such as cervicocranial and cervicobrachial pain syndromes or the well-known lumbago with sciatica. Some have described these disorders as a form of root dysfunction with neuropathic characteristics [18-22], but this had to change when in 2011, to differentiate it from nociceptive pain, neuropathic pain was redefined [23-25] by introducing two changes in its description: 1) The word 'dysfunction' was removed, and 2) the involvement of the nervous system must be a lesion or disease of the

${ }^{*}$ Correspondence to: Tomas Nakazato, Specialist in Physical Medicine and Rehabilitation. Medical Director of Cedomuh (Specialized Clinic in Muscle and Bone Pain), Lima, Peru. Head Professor of Physical Medicine and Rehabilitation, University of Piura (UDEP), Lima, Peru. Former Vice President of the Peruvian Society of Physical Medicine and Rehabilitation. Member of the Peruvian Chapter of the International Association for the Study of Pain. Lima, Peru, E-mail: tomasnakazato@yahoo.com

Keywords: segmental sensitization, primary chronic pain, musculoskeletal pain, radiculopatbic, nociplastic

Received: October 10, 2021; Accepted: October 26, 2021; Published: October 31,2021 
somatosensory system [26]. This meant that the regional symptoms described above could no longer be classified as neuropathic or radiculopathy. Other frequent syndromes, such as fibromyalgia, complex chronic regional pain syndrome type $\mathrm{I}$, and irritable bowel, were also left in limbo, since they do not present a structural lesion or disease of the nervous system demonstrable by imaging, neurophysiological and serological studies, or biopsies. Therefore, the vast majority of chronic pain disorders no longer had a mechanistic descriptor to identify them. This problem was corrected in 2017, when a third descriptor was coined to fill the gap: nociplastic pain, which was defined as "pain that arises from altered nociception despite no clear evidence of actual or threatened tissue damage causing the activation of peripheral nociceptors or evidence for disease or lesion of the somatosensory system causing the pain" [27-29]. What is the origin of non-specific chronic pain of the nociplastic type that covers a region of the spine with radiation to the trunk or extremities? The answer, in many of these cases, is spinal segmental sensitization (SSS).

What is SSS? It can be defined as 'A chronic regional pain syndrome characterized by the presence of peripheral and central sensitization phenomena, which are produced by the persistent bombardment of nociceptive impulses from an unstable joint and/or tissue lesions, and which involves one or more adjacent segments of the spinal column, its corresponding spinal nerves (nerve roots) and all the metameres that these innervate, with predominance of the integumentary and musculoskeletal systems.' The observation of this clinical picture is not new. In 1874, Dr Andrew Taylor Still, founder of osteopathy, described alterations in a segment of the spine that caused symptoms and signs in the internal organs and extremities, which he called 'osteopathic lesions' [30]. Since bone or joint injuries could not be identified once imaging methods were developed, the term was changed to 'somatic dysfunction' [31,32]. This disorder was also observed in chiropractic (a derivation of osteopathy) and acupuncture (which originated in ancient Asian medicine) $[33,34]$. These alternative therapies continue to be the subject of controversy because their original concepts predate modern medicine, and even today there is a divide between those who practice them strictly following the original empirical principles and those who are trying to adapt them to the scientific method $[35,36]$. Despite being controversial, many patients with chronic pain opt for alternative therapies because they do not find relief with conventional treatment. Dr Andrew Fischer (specialist in physical medicine and rehabilitation) coined the term SSS in 1997 [37] when publishing a description based on the work of Drs Robert Maigne [38] (who practised osteopathy) and C. Chan Gunn [22,39] (who developed an intramuscular stimulation system with acupuncture needles). As there is no obvious damage to the somatosensory nervous system and it has a tendency to perpetuate if not properly treated, we consider SSS a type of primary chronic regional pain, according to the ICD-11 [40], of the nociplastic type.

\section{Pathophysiology of SSS}

Pain is an unpleasant sensory and emotional experience associated with or resembling that associated with actual or potential tissue damage [27]. The reaction of our body to it is a response of interconnected networks that regulate each other and that include the inhibition/repression or the stimulation/expression of multiple physiological processes to maintain or restore homeostasis [41]. Therefore, the persistence of a stimulus that can cause or is already causing tissue damage will exert on this system an effect of amplification of the nociceptive signals, known as sensitization, which is defined as a 'reduction in the threshold and an increase in the magnitude of the response to the harmful stimulus, which can develop into spontaneous activity' [27], alerting the central nervous system. Not only are the nociceptors affected, producing hyperalgesia, but other receptors that encode sensory modalities such as touch and pressure may be involved [42], so that stimuli that previously did not produce a nociceptive response now begin to do so, which manifests as allodynia. These phenomena, which occur at the levels of the peripheral and central nervous system, represent adaptive physiological protective mechanisms that can configure a nosological entity, such as SSS. In this picture, nociceptive processing is intensified, usually in areas that classically compromise one or more contiguous metameric segments with signs of hyperalgesia and allodynia. We recognize four key pathophysiological factors that lead to SSS, which may act sequentially or at the same time (Figure 2).

\section{Factor 1: Instability of a spinal segment as a source of potential or actual damage}

The vertebral segment is formed by a complex of three joints (two vertebral bodies with their intervertebral disc and a pair of facet joints) [43]. Its instability can be functional or mechanical [44] and is produced by the presence of abnormal loads that alter or injure the passive stabilization system of the vertebrae, which consists of ligaments, the annulus fibrosus, and joint capsules. These loads can be static, produced by poor posture, or dynamic, produced by repetitive loads or excessive stresses $[45,46]$. Degenerative disorders and various diseases (such as autoimmune diseases, tumours, or infections) are other factors that can lead to instability [47-49]. Instability is compensated for by the muscles surrounding the vertebral segment [50-52], which are shortened by a simultaneous contraction stimulated by agonists and antagonists [53]. If the situation does not improve, the mechanical nociceptors will be stimulated by direct compression [44,54]. This stimulation is magnified when inflammation occurs in these tissues [55] and generates peripheral sensitization via the production of chemical mediators that affect the polymodal and silent nociceptors, making them mechanosensitive [56].

\section{Factor 2: Root suffering with neural dysfunction}

The paraspinal muscles try to maintain the stability of the vertebral segment, but their shortening can in turn produce the narrowing of the intervertebral or neural foramen by a lever mechanism, in which the facet joints constitute the fulcrum. In this way, the nerve root is compressed [37,53]. This is aggravated if there is concomitant bad posture (hyperlordosis, scoliosis), discopathy (degenerations, disc prominences), or stenosis (due to osteophytes or ligament thickening), among other disorders [22]. At the level of the S1 and S2 roots, where there is no participation of the vertebral segment, instability of the sacroiliac joint and sciatic nerve root compression by the piriformis muscle may be involved [57,58]. This will lead to root suffering due to impaired transport of nutrients to the neural tissue (by affecting the circulation of spinal fluid and blood in the perineurium) and an inflammatory response at this level [18,21,59-61], which will lead to sensory and motor hypersensitivity. Therefore, not only will hyperalgesia and allodynia occur in the territory innervated by the nerve root, but the corresponding peripheral muscles may also be sensitized to circulating acetylcholine, resulting in tight bands and myofascial trigger points in the myotome $[22,62]$. The spinal ganglion, which is part of the nerve root, may also be involved. This structure houses the neuronal bodies of the afferent sensory pathway of the peripheral nervous system, enveloped by satellite glial cells that protect and regulate them [63]. As a consequence of mechanical compression, these glial cells can release inflammatory substances (such as cytokines) due to the threat of damage, decreasing the threshold of the sensory 
Nakazato T (2021) Spinal segmental sensitization as a common origin of chronic non-specific regional musculoskeletal pain: Review of its pathophysiology and diagnosis

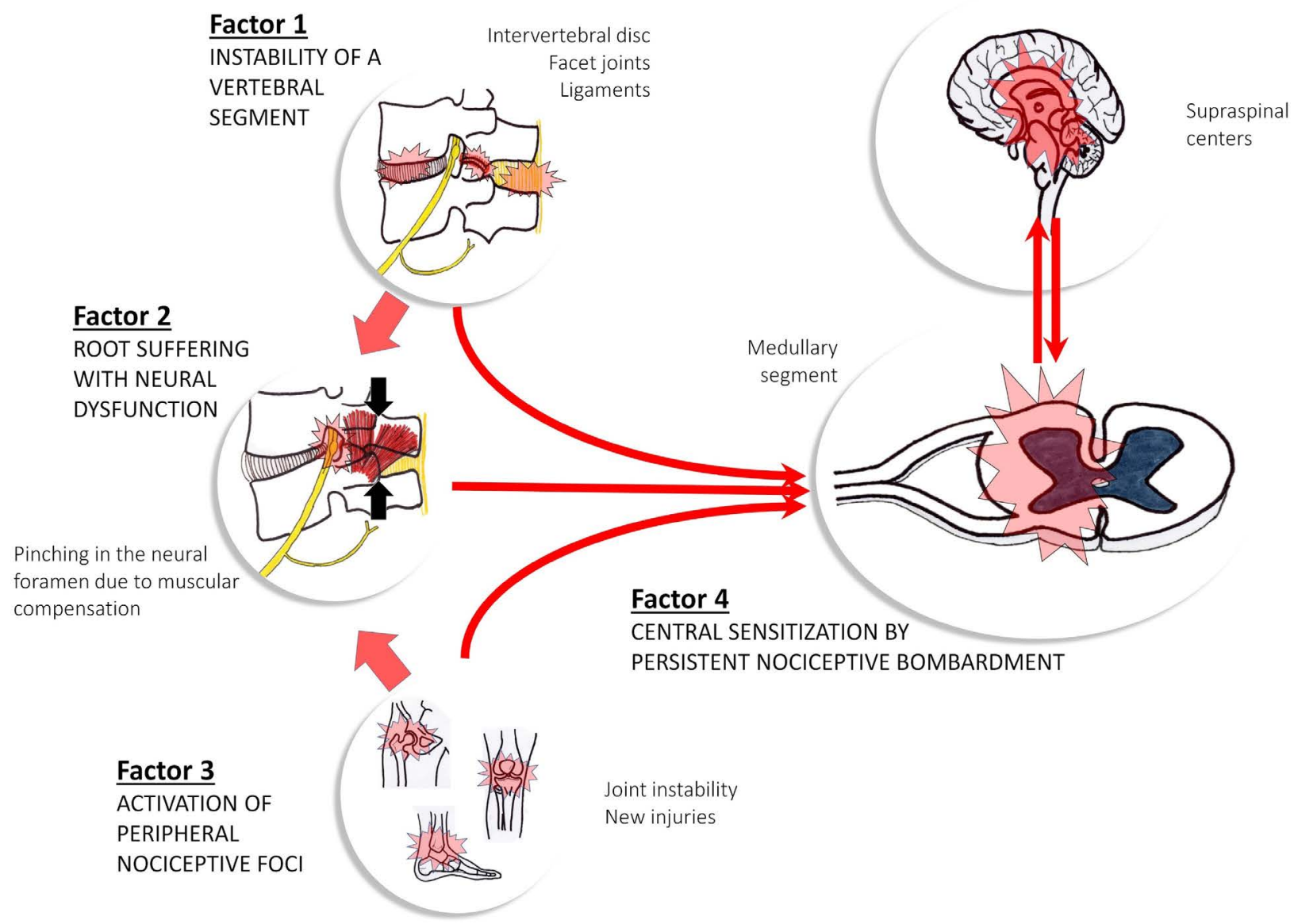

Figure 2. Four key pathophysiological factors of SSS: The instability of a spinal segment (factor 1) produces paraspinal muscle shortening to compensate. Paraspinal muscle shortening in turn narrows the intervertebral foramen, leading to root suffering (factor 2). The resulting peripheral sensitization affecting the corresponding metamere activates peripheral nociceptive foci (old and new), exacerbating the clinical picture (factor 3 ). All three factors produce a persistent bombardment of nociceptive inputs towards the corresponding medullary segment, generating central sensitization phenomena (factor 4).

Table 1. Proposed new diagnostic criteria for SSS.

DEFINITION. Chronic regional pain syndrome characterized by the presence of peripheral and central sensitization phenomena, which involve one or more contiguous vertebral segments, their spinal nerves (nerve roots), and the entire metamere they innervate, with predominance of the integumentary and musculoskeletal systems. To make the diagnosis, the following criteria must be met:

A. ANAMNESIS (interrogation). Having the following 2 (two) symptoms.

1. Chronic pain. At least 3 (three) months in duration.

2. Regional pain and of metameric distribution. Should include a region of the spine and a related peripheral region.

B. CLINICAL EXAMINATION. Must have at least 4 (four) of the following 6 (six) signs, corresponding to the anamnesis (A.2.).

- Structures innervated by the posterior branch of the spinal nerve (nerve root).

1. Dermatome: Pain on pinching/rolling pain and/or on friction with the finger at the level of the skin and subcutaneous cell tissue within $10 \mathrm{~cm}$ on both sides of the midline of the back.

2. Myotome: Pain on palpation of trigger points and/or tight myofascial bands of paraspinal muscles.

3. Sclerotome: Pain on palpation of the supra- and/or interspinous ligament.

Structures innervated by the anterior branch of the spinal nerve (nerve root).

4. Dermatome': Pain on pinching/rolling and/or friction at the peripheral level (outside the $10 \mathrm{~cm}$ of the midline of the back - at the level of the lateral/anterior trunk and/or extremities).

5. Myotome ${ }^{2}$ : Pain on palpation of trigger points and/or tight myofascial bands of non-paraspinal muscles.

6. Sclerotome ${ }^{3}$ : Pain on palpation and/or mobilization of ligaments, tendons, joints, and/or the periosteum, unrelated to the spine.

${ }^{1}$ For examination of dermatomes, the Keegan and Garret scheme is used [52].

${ }^{2}$ To identify trigger points and tight myofascial bands, the test of Travell and Simons is used [94]

${ }^{3}$ For the examination of the sclerotome, the distribution according to Inman and Saunders is used [57] [41]. 
neurons, affecting the entire corresponding root segment $[64,65]$, and aggravating the peripheral sensitization with neurogenic symptoms and signs without axonal damage. Spinal ganglion neurons also send collaterals to the prevertebral sympathetic ganglia [66], so autonomic hypersensitivity can be concomitantly found in the affected segment [67]. This condition can compromise one or several adjacent segments of the spine and its nerve roots, which innervate the corresponding metameres [68,69], producing sensory, motor, and autonomic symptoms and signs without clear evidence of injury in routine electrophysiological studies (electromyography and nerve conduction velocity tests).

\section{Factor 3: Activation of peripheral nociceptive foci}

The resulting sensitization can affect some or all of the tissues of the metameres involved, amplifying the sensory stimuli [70,71], with which any new threats of damage or injury in tissues located within the compromised metamere will exert positive feedback on the central nervous system, further exacerbating the clinical picture [36,72,73]. This can lead to confusion since new lesions by themselves are not severe enough to explain the magnitude of pain and disability manifested by the patient if we do not consider the existence of concomitant SSS. Painful behaviour, exaggerated in the eyes of the observer who has not experienced this syndrome, can cause it to be classified improperly as a psychogenic disorder or even malingering $[74,75]$.

\section{Factor 4: Central sensitization by persistent nociceptive bombardment}

Joint instability, nerve root suffering, and peripheral foci produce a persistent barrage of nociceptive impulses towards the corresponding medullary segment, generating central sensitization phenomena [7678] that will further affect the metamere, which has already been harmed by the nerve root compromise. This leads to alterations in medullary and supraspinal sensory processing and descending antinociceptive mechanisms, increased activity of nociceptive facilitatory pathways, temporal summation of secondary pain, and long-term potentiation of neuronal synapses in the anterior cingulate cortex [79]. The supraspinal centres that normally produce descending inhibitory effects in the posterior horn of the spinal cord $[79,80]$ will instead favour its activity through the descending facilitatory modulatory circuitry, which aggravates the development of persistent pain initially produced in the periphery [81-83]. This mechanism will increase the alertness of the central nervous system, warning the brain that a structure in the body is under threat of damage or is being increasingly injured and that it is not being adequately treated. Therefore, other brain centres that govern the perception of pain, emotions, and painful behaviour will also begin to activate, which can be misinterpreted as psychogenic pain, when in reality, it is SSS that is causing the cognitive and behavioural disorders [84]. The central nervous system perceives that something is not working well and hence activates its alarms to find a solution. The problem occurs when the doctor who sees the patient does not consider this full clinical picture.

\section{Diagnosis of SSS}

SSS is diagnosed by anamnesis and physical examination, since sensitization is not detected by auxiliary tests, and it is not excluded by the concomitant presence of other, defined painful disorders because any lesion or disease that produces nociceptive stimuli in the sensitized metameric segment can aggravate the clinical picture. SSS has been diagnosed using Fischer's diagnostic criteria [85-88], which have the drawback of not having been established operationally, so the professional who uses them typically makes a particular interpretation of them. In addition, it is difficult to evaluate all the characteristics in daily medical practice, where time is a critical factor. These have been, in our opinion, the main obstacles preventing more research on SSS. To avoid these shortcomings, we have developed a set of diagnostic criteria based on an internship with the late Dr Fischer and more than 20 years of managing SSS. A first attempt was made in 2014 [89,90], and the criteria were perfected in 2019 [91]. To elaborate the criteria, we took two diagnostic schemes as references: complex chronic regional pain syndrome type I (CRPS I) [92] and fibromyalgia syndrome [93], which are recognized nociplastic clinical disorders. We included symptoms and signs that correspond to the posterior branch (which innervates the structures related to the spine) and the anterior branch of the nerve root which forms the plexuses and peripheral nerves of the rest of the body for the diagnosis of SSS [94]. Both the posterior and anterior rami innervate structures of the corresponding dermatome, myotome, and sclerotome. The nerve root also has sympathetic innervation. Sensitization produces several important autonomic disorders, such as trophoedema (microedema or 'neurogenic oedema'), peripheral vasoconstriction ('coldness'), piloerection ('goosebumps'), increased sweating (leading to decreased cutaneous electrical impedance), and trophic changes in the skin $[22,37,38]$. These signs are particularly important in the clinical picture of the patient but are not decisive for the diagnosis, so we have preferred to leave them aside in our proposal to shorten the time needed to perform the examination. The set of criteria proposed for the diagnosis of SSS is detailed in Table 1, and an example of its application is shown in Figure 3.

Patients rarely have involvement of a single metameric segment, so we have grouped the diagnoses into 10 clinical pictures for practical

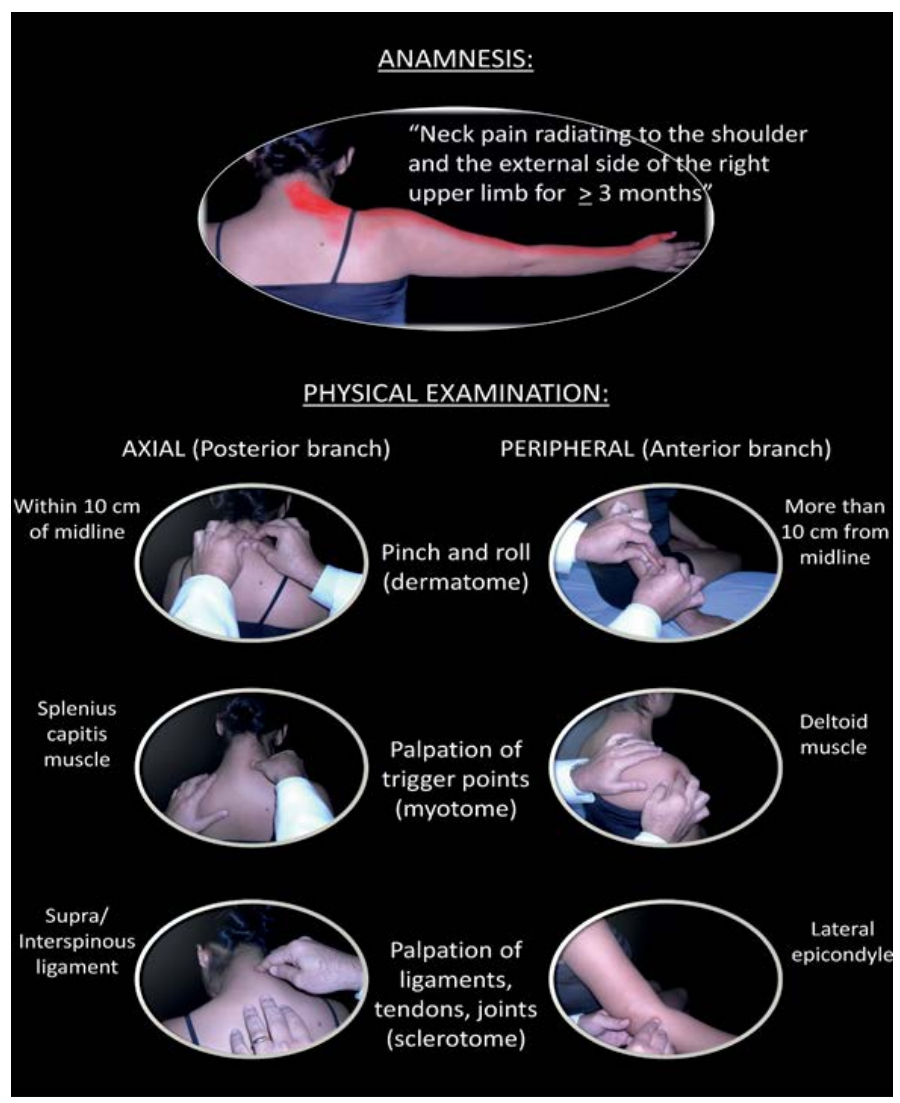

Figure 3. Example of diagnosis of a right lower cervical (C6) SSS using the new set of diagnostic criteria. 
Table 2. SSS segments.

\begin{tabular}{|c|c|c|c|}
\hline & Name & Nerve roots & Distribution of regional pain \\
\hline 1. & Upper-cervical & $\mathrm{C} 2-\mathrm{C} 3$ & Neck pain radiating to the head. \\
\hline 2. & Mid-cervical & $\mathrm{C} 4-\mathrm{C} 5$ & $\begin{array}{l}\text { Neck pain radiating to the front of the shoulder, } \\
\text { arm, and back of the chest. }\end{array}$ \\
\hline 3. & Lower-cervical & C6-C7 & $\begin{array}{l}\text { Neck pain radiating to the outer and posterior side } \\
\text { of the shoulder, arm, forearm, and hand. }\end{array}$ \\
\hline 4. & Cervico-thoracic & $\mathrm{C} 8-\mathrm{T} 1$ & $\begin{array}{l}\text { Neck and back pain radiating to the inner side of } \\
\text { the shoulder, arm, forearm, and hand. }\end{array}$ \\
\hline 5. & Upper-thoracic & T2-T4 & Back pain radiating to the chest wall. \\
\hline 6. & Mid-thoracic & T5-T8 & Back pain radiating to the upper hemiabdomen. \\
\hline 7. & Lower-thoracic & T9-T11 & Back pain radiating to the lower hemiabdomen. \\
\hline 8. & Lumbo-thoracic & T12-L1 & $\begin{array}{l}\text { Back pain radiating to the pelvis and inguinal } \\
\text { region. }\end{array}$ \\
\hline 9. & Lumbar & L2-L4 & $\begin{array}{l}\text { Low-back pain radiating to the anterointernal } \\
\text { aspect of the thigh and knee, and the internal aspect } \\
\text { of the leg. }\end{array}$ \\
\hline 10. & Lumbo-sacral & L5-S2 & $\begin{array}{l}\text { Low-back pain radiating to the posterolateral } \\
\text { aspect of the thigh, leg, and entire foot. }\end{array}$ \\
\hline
\end{tabular}

purposes (Table 2). A preliminary study we conducted showed that the proposed new criteria had a sensitivity of $88 \%$, a specificity of $64 \%$, and a moderate inter-examiner reliability (Cohen's kappa value of 0.535 ) with respect to the diagnosis based on Fischer [95]. We calculated that $41.6 \%$ of patients who came to our outpatient clinic for chronic musculoskeletal pain had SSS, and it was more frequent in women (71.4\%). The most frequent segment was the lumbosacral segment (L5-S2), followed by the mid-cervical segment (C4-5) and the lumbar segment (L2-L4) [90-98]. The radiated pain in SSS does not usually have the traditionally described root pattern, since the patient does not typically refer to the pain only according to the dermatomic distribution; rather, pain can also manifest in the structures corresponding to the myotome, sclerotome, as well as the angiotome and viscerotome, which are not necessarily below the affected dermatome. In addition, due to their spinal interconnections, it is common for more than one segment to be sensitized simultaneously, producing pain patterns that vary between patients.

Within the differential diagnosis, the radiculopathies defined with neurophysiological studies should be considered an aetiological cause of SSS if the criteria for its diagnosis are met. Some accepted regional entities, despite not having a defined aetiology, are in our opinion variants of SSS, such as Arnold's neuralgia (upper cervical segment C2C3), and piriformis muscle syndrome (lumbosacral segment L5-S2). A particularly striking scenario is CRPS I, which could represent a severe form of SSS. The entrapment of peripheral nerves (such as those present in thoracic outlet syndrome, carpal and tarsal tunnel syndromes, or meralgia paresthetica) could lead to symptoms similar to SSS, but because only the fibres of the anterior branch of the nerve root (and not the posterior branch) are affected, this would not meet the diagnostic criteria. A patient with multiple injuries (for example, from a motor vehicle accident or fall) involving a region of the spine and extremities could have a positive clinical examination for SSS, but the pain usually resolves in less than three months with adequate treatment, so it would not meet the anamnesis criterion.

\section{Treatment of SSS}

The four pathophysiological factors described allow us to define three therapeutic objectives on a rational and systematic basis.

The first objective consists of peripheral desensitization and the treatment of injured tissues (factors 2 and 3 ) because they are usually the reasons why a patient comes in for a medical consultation. To do this, we can use pharmacological therapies that include non-steroidal anti-inflammatory drugs (NSAIDs), corticosteroids, opioid and nonopioid analgesics, and adjuvants such as muscle relaxants, among others. Peripheral desensitization can also be achieved with electrotherapy, manual therapies, dry needling, or corticosteroid infiltrations. Peripheral lesions require physical therapy, as well as severe cases, may require surgical intervention (such as advanced gonarthrosis/ coxarthrosis or massive tendon/ligament tears). Radiation in the metamere is typically eased by decompressing the nerve root. This is achieved by performing a paraspinal block with lidocaine described by Fischer $[37,85]$ which relaxes the muscles innervated by the posterior branch [99]. This procedure usually produces immediate relief of many of the radiated symptoms, but it is important to locate the compromised segment for it to be effective. Other options are the application of a dry needle into the paraspinal muscles according to Gunn and others, which can also relax the musculature by mechanical stimulation $[39,97,100$ $102]$, and vertebral manipulations as proposed by Maigne and others $[38,68,103]$. Other therapies, such as thermotherapy, electrotherapy, deep massage [104], or vertebral tractions, can yield similar results [105]. Decompression surgery (such as the resection of hernias of the nucleus pulposus or in spinal stenosis) may be an option for severe cases [106]. This would explain why there are so many treatments for the same phenomenon: if nerve root decompression is achieved, much of the segmental pain is alleviated.

The second objective is central desensitization (factor 4). To accomplish it, we can also use the pharmacological treatment described in the first objective, combining it with pain modulators such as antidepressants (tricyclic or dual) and anticonvulsants. Nonpharmacological treatments include electrotherapy, manipulations, acupuncture, and massage therapy, which stimulate sensory receptors that release endogenous opioids and activate supraspinal and medullary inhibition $[22,103,107,108]$. Cognitive behavioural therapy, relaxation and meditation techniques, and low-impact aerobic exercise can also be useful to relieve supraspinal sensitization [109-112].

If the unstable segment of the spine is not fixed (factor 1) and the factors that condition it are not removed, the patient usually relapses. Thus, the third therapeutic objective includes ergonomic measures and orthoses to improve posture. Therapeutic exercise also contributes to this end but also improves the motor control of the paraspinal muscles by stabilizing the segment. Surgical treatment may be an option for severe instability that does not improve with conservative treatment $[44,53,55,80,113,114]$.

\section{Conclusion}

In the absence of confirmatory tests that explain regional and chronic musculoskeletal pain of metameric distribution (which includes a segment of the spine with radiation to the extremities or trunk), doctors usually tell patients that it is only a 'referred pain' or the 'consequence of stress. Worse still, doctors may begin to suspect a psychiatric disorder or malingering due to the apparently disproportionate painful behaviour in relation to the findings of the auxiliary tests. The distribution usually has radicular features but without signs of motor or sensory deficit and with normal neurophysiological exams, so it cannot be classified as neuropathic/radiculopathic. In the best scenario, only slight structural alterations are found on imaging, such as intervertebral disc dehydrations or prominences, mild spondylolisthesis, incipient spondylotic changes, or minimal postural disorders, which do not explain the symptoms and signs found if we do not take into account 
Nakazato T (2021) Spinal segmental sensitization as a common origin of chronic non-specific regional musculoskeletal pain: Review of its pathophysiology and diagnosis

the diagnosis of SSS. Since they do not obtain relief in traditional health centres, patients turn to alternative therapies. The disadvantage of these disciplines is that they still rely on conceptions that are more philosophical than scientific, in addition to basing their treatments on a single modality, such as manipulations by osteopaths and chiropractors or the application of needles by acupuncturists.

SSS gives us a new view of this clinical picture by providing a pathophysiological explanation without the ties that diagnoses originating before the establishment of modern medicine tend to have. We expect that the pathophysiological framework described here will be used to define various therapeutic strategies, including a diverse arsenal that includes drugs, physical therapy, infiltrations or nerve blocks, and even surgery, in addition to alternative treatments such as manual therapies, dry needling or acupuncture, cognitive behavioural therapy, and meditation or exercise, without any particular bias. Having a diagnostic system with standardized criteria will allow better communication among professionals who treat musculoskeletal pain and will serve as the basis for studies of patient samples and the identification of the best treatments in homogeneous samples. This will benefit a vast number of patients who suffer from this type of chronic regional pain, one of the main causes of disability worldwide.

\section{Acknowledgments}

The authors are grateful for the support of the Latin American Rehabilitation Medical Association (AMLAR), particularly of Dr Gustavo Bocca (Past-President).

\section{References}

1. Anthony M (2000) Cervicogenic headache: prevalence and response to local steroid therapy. Clin Exp Rheumatol 18: S59-S64. [Crossref]

2. Antonacci F, Sjaastad O (2011) Cervicogenic Headache: A Real Headache. Curr Neurol Neurosci Rep 11: 149-155. [Crossref]

3. Haldeman S, Dagenais S (2001) Cervicogenic headaches: a critical review. Spine J 1: 31-46. [Crossref]

4. Magnusson M, Malmströn EM (2016) The conundrum of cervicogenic dizziness. Handb Clin Neurol 137: 365-369. [Crossref]

5. Reiley AS, Vickory FM, Funderburg SE, Cesario RA, Clendaniel RA (2017) How to diagnose cervicogenic dizziness. Arch Physiother 7: 12. [Crossref]

6. Palmer KT, Smedley J (2007) Work relatedness of chronic neck pain with physical findings - a systematic review. Scand J Work Environ Health 33: 165-191. [Crossref]

7. Hagberg M (2000) Epidemiology of neck and upper limb disorders and workplace factors. Occupational Ergonomics: Work related musculoskeletal disorders of the upper limb and back. Taylor \& Francis. London.

8. Ronthal M (2004) Arm and Neck Pain. Principles of Diagnosis and Management. (4 edn), Butterworth-Heinemann. Philadelphia.

9. Jensen S (2001) Musculoskeletal causes of chest pain. Aust Fam Physician 30: 834 839. [Crossref]

10. Fam AG, Smythe HA (1985) Musculoskeletal chest wall pain. Can Med Assoc J 133: 379-389. [Crossref]

11. Jorgensen LS, Fossgreen J (1990) Back pain and spinal pathology in patients with functional upper abdominal pain. Scand J Gastroenterol 25: 1235-1241. [Crossref]

12. Sharpstone D, Colin-Jones DG (1994) Chronic, non-visceral abdominal pain. Gut 35: 833-836. [Crossref]

13. Jöud A, Petersson IF, Englund M (2012) Low back pain: Epidemiology of consultations. Arthritis Care Res 64: 1084-1088. [Crossref]

14. Fatoye F, Gebrye T, Odeyemi I (2019) Real-world incidence and prevalence of low back pain using routinely collected data. Rheumatol Int 39: 619-626. [Crossref]

15. Konstantinou K, Dunn KM (2008) Sciatica: Review of Epidemiological Studies and Prevalence Estimates. Spine 33: 2464-2472. [Crossref]
16. Valat JP, Genevay S, Marty M, Rozenberg S, Koes B (2010) Sciatica. Best Pract Res Clin Rheumatol 24: 241-252. [Crossref]

17. Maixner W, Fillingim RB, Williams DA, Smith SB, Slade GD (2016) Overlapping chronic pain conditions: Implications for diagnosis and classification. J Pain 17: T93-T107. [Crossref]

18. Olmarker K, Rydevik B (1991) Pathophysiology of sciatica. Orthop Clin Nort Am 22: 223-234. [Crossref]

19. Bertilson B, Grunnesjö M, Johansson SE, Strender LE (2007) Pain drawing in the assessment of neurogenic pain and dysfunction in the neck/shoulder region: Interexaminer reliability and concordance with clinical examination. Pain Med 8: 134-146. [Crossref]

20. Eubanks JD (2010) Cervical radiculopathy: Nonoperative management of neck pain and radicular symptoms. Am Fam Physician. 81: 33-40. [Crossref]

21. Slipman CW, Isaac Z, Lenrow DA, Chou LH, Gilchrist RW, et al. (2002) Clinical evidence of chemical radiculopathy. Pain Physician 5: 260-265. [Crossref]

22. Gunn CC (1996) The Gunn Approach to the Treatment of Chronic Pain: Intramuscular Stimulation for Myofascial Pain of Radiculopathic Origin New York: Churchill Livingstone.

23. International Association for the Study of Pain (IASP) IASP Terminology.

24. Treede R, Jensen TS, Campbell JN, Cruccu G, Dostrovsky JO, et al. (2008) Neuropathic pain: Redefinition and a grading system for clinical and research purposes. Neurology 70: 1630-1635. [Crossref]

25. Loeser JD, Treede RD (2008) The Kyoto protocol of IASP Basic Pain Terminology. Pain 137: 473-477. [Crossref]

26. Jensen TS, Baron R, Haanpää M, Eija K, Loeser J, et al. (2011) A new definition of neuropathic pain. Pain 152: 2204-2205. [Crossref]

27. https://www.iasp-pain.org/Education/Content.aspx?ItemNumber=1698\#Pain.

28. Kosek E, Cohen M, Baron R, Gebhart GF, Mico JA, et al. (2016) Do we need a third mechanistic descriptor for chronic pain states? Pain 157: 1382-1386. [Crossref]

29. Nakazato T, Quezada P (2020) Dolor nociplástico: el nuevo descriptor. Rev Hosp Jua Mex 87: 88-93.

30. Trowbridge C (1991) Andrew Taylor Still Kirksville: Truman State University Press.

31. Kuchera ML (2016) Somatic dysfunction. Textbook of Musculoskeletal Medicine. $\left(2^{\text {nd }}\right.$ edn), Oxford: Oxford University Press.

32. Nelson KE, Glonek T (2015) Somatic Dysfunction in Osteopathic Family Medicine. $2^{\text {nd }}$ edn. Baltimore: Wolters Kluwer Health.

33. Ricard F, Sallé JL (2003) Tratado de Osteopatía. ( $3^{\text {rd }}$ edn), Madrid: Editorial Médica Panamericana, SA.

34. Stux G, Berman B, Pomeranz B (2003) Basics of Acupuncture. ( $5^{\text {th }}$ edn), SpringerVerlag. Berlin.

35. Ernst E (2008) Chiropractic: A Critical Evaluation. J Pain Symptom Manage 35: 544 562. [Crossref]

36. Yin C, Buchhelt TE, Park JJ (2017) Acupuncture for chronic pain: an update and critical overview. Curr Opin Anaestesiol 30: 583-592. [Crossref]

37. Fischer AA (1997) New developments in diagnosis of myofascial pain and fibromyalgia. Phys Med Rehab Clin N Am 8: 1-21.

38. Maigne R (1996) Diagnosis and Treatment of Pain of Vertebral Origin: A Manual Medicine Approach. ( $1^{\text {st }}$ edn), Williams \& Wilkins. Baltimore.

39. Gunn CC (1997) Radiculopathic Pain: Diagnosis and Treatment of Segmental Irritation or Sensitization. J of Musculoskeletal Pain 5: 119-216.

40. Treede RD, Rief W, Barke A, Aziz Q, Bennett MI, et al. (2015) A classification of chronic pain for ICD-11. Pain 156: 1003-1007. [Crossref]

41. Borsook D, Youssef AM, Simons L, Elman I, Christopher E (2018) When pain gets stuck: the evolution of pain chronification and treatment resistance. Pain 159: 24212436. [Crossref]

42. Gold MS, Gebhart GF (2010) Nociceptor sensitization in pain pathogenesis. Nat Med 16: 1248-1257. [Crossref]

43. Iorio JA, Jakoi AM, Singla A (2016) Biomechanics of Degenerative Spinal Disorders Asian Spine J 10: 377-384. [Crossref] 
Nakazato T (2021) Spinal segmental sensitization as a common origin of chronic non-specific regional musculoskeletal pain: Review of its pathophysiology and diagnosis

44. Beazell JR, Mullins M, Grindstaff TL (2010) Lumbar instability: an evolving and challenging concept. J Man and Manip Ther 18: 9-14. [Crossref]

45. Viidik A (1973) Functional properties of collagenous tissues. Int Rev Connect Tissu Res 6: 127-215. [Crossref]

46. Solomonow M, Zhou BH, Baratta RV, Burger E (2003) Biomechanics and electromyography of a cumulative lumbar disorder: response to static flexion. Clin Biomech 18: 890-898. [Crossref]

47. Panjabi MM (1992) The stabilizing system of the spine. Part I. Function, disfunction, adaptation, and enhancement. J Spinal Disord 5: 383-389. [Crossref]

48. Tkaczuk H (1968) Tensile properties of human lumbar longitudinal ligaments. Acta Orthop Scand 15: 1-69. [Crossref]

49. Rissanen PM (1960) The surgical anatomy and pathology of the supraspinous and interspinous ligaments of the lumbar spine with special reference to ligament ruptures. Acta Orthop Scand 46: 1-100. [Crossref]

50. Panjabi MM (2006) A hypothesis of chronic back pain: ligament subfailure injuries lead to muscle control dysfunction. Eur Spine J 15: 668-676. [Crossref]

51. Solomonow M, Zhou BH, Harris M, Lu Y, Baratta RV (1998) The ligamento-muscular stabilizing system of the spine. Spine 23: 2552-2562. [Crossref]

52. Sihvonen T (1995) Low back pain, paraspinal EMG and forgotten dorsal rami. Kuopio: Kuopio University Publications D. Medical Sciences.

53. Panjabi MM (2006) A hypothesis of chronic back pain: ligament subfailure injuries lead to muscle control dysfunction. Eur Spine J 15: 668-676. [Crossref]

54. Panjabi MM (2003) Clinical spinal instability and low back pain. $J$ Electromyogr Kinesiol 13: 371-379. [Crossref]

55. Solomonow M (2006) Sensory - Motor control of ligaments and associated neuromuscular disorders. J Electromyogr Kinesiol 16: 549-567. [Crossref]

56. Gómez Esquer F (2016) Structural bases and anatomy of pain. Fundamentals, Evaluation and Treatment. Madrid: Editorial Médica Panamericana, S.A.

57. Fortin JD, Vilensky JA, Merkel GJ (2003) Can the sacroiliac joint cause sciatica? Pain Physician 6: 269-271. [Crossref]

58. Baloh RW (2019) Sciatica and Chronic Pain: Past, Present and Future Los Angeles: Springer International Publishing AG.

59. Garfin SR, Rydevik B, Lind B, Massie J (1976) Spinal nerve root compression. Spine 20: 1810-1820. [Crossref]

60. Cornefjord M, Olmarker K, Otani K, Rydevik B (2002) Nucleus pulposus-induced nerve root injury: effects of diclofenac and ketoprofen. Eur Spine J 11: 57-61. [Crossref]

61. Rothman SM, Winkelstein BA (2007) Chemical and mechanical nerve root insults induce differential behavioral sensitivity and glial activation that are enhanced in combination. Brain Res 1181: 30-43. [Crossref]

62. Kawashima K, Kajiyama K, Fujimoto K, Oohata H, Suzuki T (1993) Presence of acetylcholine in blood and its localization in circulating mononuclear leukocytes of humans. Biog Amines 9: 251-258.

63. Martín Fontelles MI (2016) Neurobiology of pain: peripheral and spinal molecular mechanisms. Pain Medicine Manual: Fundamentals, Evaluation and Treatment. Madrid: Editorial Médica Panamericana, SA.

64. Ahimsadasan N, Reddy V, Kumar A (2020) Neuroanatomy, Dorsal Root Ganglion. In: StatPearls. Treasure Island (FL): StatPearls Publishing.

65. Krames ES (2014) The Role of the Dorsal Root Ganglion in the Development of Neuropathic Pain. Pain Medicine 15: 1669-1685. [Crossref]

66. Matthews MR, Cuello A (1982) Substance P-immunoreactivite peripheral branches of sensory neurons innevate guinea pig sympathetic neurons. Proc Natl Acad Sci USA 79: 1668-1672. [Crossref]

67. Gunn CC, Milbrandt WE (1978) Early and subtle signs in low-back sprain. Spine 3: 267-281. [Crossref]

68. Arlen A (1990) Metameric medicine and atlas therapy. Back Pain. Springer. Dordrecht.

69. Izzo R, Guarnieri G, Guglielmi G, Muto M (2013) Biomechanics of the spine. Part I: Spinal stability. Eur J Radiol 82: 118-126. [Crossref]

70. Latremoliere A, Woolf CJ (2009) Central sensitization: A generator of pain hypersensitivity by central neural plasticity. J Pain 10: 895-926. [Crossref]

71. Woolf CJ (2011) Central sensitization: Implications for the diagnosis and treatment of pain. Pain 152: S2-15. [Crossref]
72. Fernández-de-las-Peñas C, Dommerholt J (2014) Myofascial trigger points: Peripheral or central phenomenon? Curr Rheumatol Rep 16: 395. [Crossref]

73. Ashmawi HA, Góes Freire GM (2016) Peripheral and central sensitization. Rev Dor Sao Paulo 17: S31-S34.

74. Blackburn-Munro G, Blackburn-Munro RE (2001) Chronic pain, chronic stress and depression: Coincidence or consequence? J Neuroendocrinol 13: 1009-1023. [Crossref]

75. Simons L, Elman I, Borsook D (2014) Psychological processing in chronic pain: A neural systems approach. Neurosci Biobehav Rev 39: 61-78. [Crossref]

76. Baron R, Hans G, Dickenson AH (2013) Peripehral imput and its importance for central sensitization. Ann Neurol 74: 630-636. [Crossref]

77. Melzack R, Coderre TJ, Katz J, Vaccarino AL (2001) Central Neuroplasticity and Pathological Pain. Ann N Y Acad Sci 933: 157-174. [Crossref]

78. Coderre TJ, Katz J, Vaccarino AL, Melzack R (1993) Contribution of central neuroplasticity to pathological pain: review of clinical and experimental evidence. Pain 52: 259-285. [Crossref]

79. Nijs J, Daenen L, Cras P, Struyf F, Roussel N, et al. (2012) Nociception affects moto output. A review on sensory-motor interaction with focus on clinical implications. Clin $J$ Pain 28: 175-181. [Crossref]

80. Fields HL, Basbaum AI (1999) Central nervous system mechanisms of pain modulation. Textbook of Pain. Churchill Livingstone.

81. Feng W, Guo W, Zou S, Ren K, Dubner R (2008) Supraspinal glial-neuronal interactions contribute to descending pain facilitation. $J$ Neurosci 28: 10482-10495. [Crossref]

82. Porreca F, Ossipov MH, Gebhart GF (2002) Chronic pain and medullary descending facilitation. Trends Neurosci 25: 319-325. [Crossref]

83. Sprenger C, Bingel U, Büchel C (2011) Treating pain with pain: Supraspinal mechanisms of endogenous analgesia elicited by heterotopic noxius conditioning stimulation. Pain 152: 428-439. [Crossref]

84. Moseley GL, Flor H (2012) Targeting cortical representations in the treatment of chronic pain: A review. Neurorehabil Neural Repair 26: 646-652. [Crossref]

85. Fischer AA, Imamura M, Dubo H, Cassius D (2008) Spinal Segmental Sensitization. (3rd edn), Physical Medicine \& Rehabilitation Secrets. Mosby. New York.

86. Unverzagt C, Berglund K, Thomas JJ (2015) Dry needling for myofascial trigger point pain: A clinical commentary. Int J Sports Phys Ther 10: 402-418. [Crossref]

87. Suputtitada A (2016) Myofascial pain syndrome and sensitization. J Phys Med Rehab Res 1: 2-4.

88. Shah JP, Thaker N (2018) Myofascial Pain Syndrome. Fundamentals of Pain Medicine. Cham: Springer International Publishing AG.

89. Nakazato T, Camacho G (2014) Spinal Segmental Sensitization Syndrome as a Common Cause of Chronic Musculoskeletal Pain: A Case Series Study. PMR 6: S143.

90. Nakazato T, Quezada P, Alarcón R (2020) Spinal segmental sensitization syndrome: Prevalence in patients with chronic musculoskeletal pain in a physiatric practice using a new system of diagnostic criteria. Am J Phys Med Rehabil 99: 1-376.

91. Nakazato T, Romero P (2019) El síndrome de sensibilización espinal segmentaria nueva propuesta de criterios diagnósticos para la investigación. Rev Mex Med Fis Rehab 31: 6-12.

92. Harden RN, Bruehl S, Stanton-Hicks M, Wilson PR (2007) Proposed New Diagnostic Criteria for Complex Regional Pain Syndrome. Pain Med 8: 327-331. [Crossref]

93. Wolfe F, Smythe HA, Yunus MB, Bennet RM, Bombardier C, et al. (1990) The American College of Rheumatology 1990 Criteria for the Classification of Fibromyalgia. Report of the Multicenter Criteria Committee. Arthritis Rheum 22: 160-172. [Crossref]

94. Gallardo NJ (2008) The segmentary sensitive innervation: dermatomes, myotomes and sclerotomes. Rev Chil Anestesia 37: 26-38.

95. Nakazato T, Quezada P (2020) Spinal segmental sensitization syndrome: a pilot study to assess the reliability and diagnostic accuracy of a new set of diagnostic criteria. $\mathrm{Am}$ J Phys Med Rehab 99: 1-376.

96. Keegan J, Garret F (1948) The segmental distribution of the cutaneous nerves in the limbs of man. Anat Rec 102: 409-437. [Crossref]

97. Simons DG, Travell JG, Simons LS (1999) Travell \& Simons' Myofascial Pain and Disfunction: The Trigger Point Manual. ( $2^{\text {nd }}$ edn), Willams \& Wilkins. Baltimore.

98. Inman VT, Saunders JB (1944) Referred Pain from Skeletal Structures. J Nerv Ment Dis 99: 660-667. 
Nakazato T (2021) Spinal segmental sensitization as a common origin of chronic non-specific regional musculoskeletal pain: Review of its pathophysiology and diagnosis

99. Sihvonen T, Lindgren KA, Airaksinen O, Leino E, Partanen J, et al. (1995) Dorsal ramus irritation associated with recurrent low back pain and its relief with local anaesthetic or training therapy. J Spin Disord 8: 8-14. [Crossref]

100. Dommerholt J, Fernandez-de-las-Penas C (2018) Trigger Point Dry Needling. ( $2^{\text {nd }}$ edn), An evidence and Clinical-Based Approach. Elsevier.

101. Kalichman L, Vulfsons S (2010) Dry needling in the management of musculoskeletal pain. J Am Board Fam Med 23: 640-646. [Crossref]

102. Garvey TA, Marks MR, Wiesel SW (19898) A prospective, randomized, double-blind evaluation of trigger point injection therapy for low back pain. Spine 14: 962-964. [Crossref]

103. Zafereo JA, Deschenes BK (2015) The Role of Spinal Manipulation in Modifying Central Sensitization. J Appl Biobehav Res 20: 84-99.

104. Goats GC (1994) Massage - the scientific basis of an ancient art: part 2. Physiological and therapeutic effects. Br J Sp Med 28: 153-156. [Crossref]

105. Krause M, Refshauge KM, Dessen M, Boland R (2000) Lumbar spine traction: evaluation of effects and recommended application for treatment. Man Ther 5: 72-81. [Crossref]

106. Weinstein JN, Tosteson TD, Lurie JD, Tosteson ANA, Blood E, et al. (2008) Surgical versus nonsurgical therapy for lumbar spinal stenosis. $N$ Engl J Med 358: 794-810. [Crossref]
107. Chou LW, Kao MJ, Lin JG (2012) Probable mechanisms of needling therapies for myofascial pain control. Evid Based Complement Alternat Med 2012: 705327. [Crossref]

108. Melzack R, Wall PD (1996) The Challenge of Pain. ( $2^{\text {nd }}$ edn), Penguin Books. London.

109. Nijs J, Kosek E, Van Oosterwijck J, Meeus M (2012) Dysfunctional endogenous analgesia during exercise in patientes with chronic pain: To exercise or not to exercise? Pain Physician 15: ES205-ES213. [Crossref]

110. Lima LV, Abner TS, Sluka KA (2017) Does exercise increase or decrease pain? Central mechanisms underlying these two phenomena. $J$ Physiol 13: 4141-4150. [Crossref]

111. Astin JA (2004) Mind body therapies for the management of pain. Clin J Pain 20 27-32. [Crossref]

112. Bushnell MC, Ceko M, Low LA (2016) Cognitive and emotional control of pain and its disruption in chronic pain. Nat Rev Neurosci 14: 502-511. [Crossref]

113. Fritz JM, Erhard RE, Hagen BF (1998) Segmental instability of the lumbar spine. Phys Ther 78: 889-896. [Crossref]

114. Sarker KK, Sethi J, Mohanty U (2020) Comparative clinical effects of spina manipulation, core stability exercise, and supervised exercise on pain intensity, segmental instability, and health-related quality of life among patients with chronic nonspecific low back pain: A randomized trial. J Nat Sc Biol Med 11: 27-34.

Copyright: $\odot 2021$ Nakazato T. This is an open-access article distributed under the terms of the Creative Commons Attribution License, which permits unrestricted use, distribution, and reproduction in any medium, provided the original author and source are credited. 